\title{
Mortality Pattern Among Patients Admitted to the Intensive Care Unit in a Tertiary Health Institution in Abuja - Nigeria: 18-year Review
}

\author{
Christie Omolola Adams ${ }^{1}$, , Ebenezer Obi Daniel², Abubakar Zainab Galadima1, \\ Imam Abubakar ${ }^{1}$, Esther Joseph ${ }^{1}$, Grace Shedul ${ }^{1}$, Nicholas Baamlong1, Mustapha Jamda ${ }^{1}$, \\ Ahmed Mamuda Bello ${ }^{2}$, Paul Olaiya Abiodun ${ }^{2}$, Israel Olukayode Popoola ${ }^{3}$, Kabir Yunusa Amari ${ }^{4}$, \\ Christiana Asibi Ogben ${ }^{2}$
}

${ }^{1}$ University of Abuja Teaching Hospital, Abuja, Nigeria

${ }^{2}$ Department of Public Health, Texila American University, Georgetown, Guyana

${ }^{3}$ Department of Epidemiology and Community Health, University of Ilorin, Ilorin, Nigeria

${ }^{4}$ Department of Psychology, Benue State University, Makurdi, Nigeria

Email address:

loladams28@gmail.com (C. O. Adams)

${ }^{*}$ Corresponding author

\section{To cite this article:}

Christie Omolola Adams, Ebenezer Obi Daniel, Abubakar Zainab Galadima, Imam Abubakar, Esther Joseph, Grace Shedul, Nicholas Baamlong, Mustapha Jamda, Ahmed Mamuda Bello, Paul Olaiya Abiodun, Israel Olukayode Popoola, Kabir Yunusa Amari, Christiana Asibi Ogben. Mortality Pattern Among Patients Admitted to the Intensive Care Unit in a Tertiary Health Institution in Abuja - Nigeria: 18-year Review. Journal of Family Medicine and Health Care. Vol. 7, No. 3, 2021, pp. 77-82. doi: 10.11648/j.jfmhc.20210703.13

Received: August 28, 2021; Accepted: September 18, 2021; Published: October 12, 2021

\begin{abstract}
Background: It is globally known that, there is high mortality rate in the Intensive Care Unit. Therefore, this study seeks to know the pattern of mortality and the associated variables at the University of Abuja Teaching Hospital. Method: A descriptive cross-sectional retrospective study was conducted among patients admitted into the Intensive Care Unit, University of Abuja Teaching Hospital between May 2002 and April 2020. A total of 2078 patients admitted within the study period was analyzed. Data was collected from the ICU admission and discharge register using a proforma to include socio-demographic characteristics like gender, age, occupation, and religion. Data was analyzed using SPSS version 26.0. Variables were summarized and presented as frequencies and percentages, while quantitative variables were represented using means and standard deviations. The association between categorical variables was tested using Chi-square at a P-value of significance $<0.05$. And purposeful sampling was used to rule out bias. Result: The number of female patients were 1062 (51.1\%) while $1016(48.9 \%)$ were males. A total of $1362(65.5 \%)$ of the patients were successfully managed and transferred to the general wards for further management, while 716 (34.5\%) died in the ICU and were transferred to the Mortuary. Conclusion: This study represents the pattern and frequency of death rate of patients admitted into the Intensive Care Unit. Further study involving data analysis on the causes of death will be highly informative and beneficial.
\end{abstract}

Keywords: Intensive Care Unit, Mortality, Pattern

\section{Introduction}

An Intensive Care Unit is an organized system for the provision of care to the critically ill patients that needs intensive and specialized medical and nursing care. It is located in a defined geographic area of the hospital, its activities often extend beyond the walls of the physical space to include the emergency department, hospital wards, and follow-up clinics [1]. An Intensive Care Unit is usually a three-level unit and are described as thus: Level 1 ICU is capable of providing oxygen, noninvasive monitoring, and more intensive nursing care than on a ward, whereas a level 2 ICU can provide invasive monitoring and basic life support for a short period. And level 3 ICU provides a full spectrum 
of monitoring and life support technologies, serves as a regional resource for the care of critically ill patients, and may play an active role in developing the specialty of intensive care through research and education. A formal definition and descriptive framework for ICU can inform health care decision-makers in planning, measuring capacity, provide clinicians and patients with a benchmark to evaluate the level of resources available for clinical care [1]. The 3 levels of Intensive Care Unit are represented in the University of Abuja Teaching Hospital, though not separated as hospital ward or cubicles.

Consequently, the study was conducted using the records of patients admitted into the Intensive Care Unit of UATH from May 2002 to April 2020. It is a specialized unit that provides expert care to patients with life-threatening illnesses and organ supports. It was established in January 1998 as a 4bedded compact unit with 4-cardiac monitors, 5-ventilators, central piped-line oxygen, 3 functional suction machines and emergency medications for critical care at the highest level. It is located adjacent to the operating theatre complex. The ICU is staffed with 4 consultants, 10 resident doctors and 17 nurses, 6 cleaners and 6 janitors. These patients were comanaged by the Anesthetist Consultants, Resident Doctors, trained Intensive Care Nurses and the admitting Surgeon, Obstetrics/Gynecologist, Pediatricians and or Physician. The data were recorded on a proforma format sheet designed for the study and data analysis was done using Microsoft Excel 2010 and SPSS version 26.

A researcher, Blanch L further said, preference should be given to patients who are more likely to survive if admitted to the ICU but unlikely to survive or likely to have more significant morbidity if not admitted [2]. Hence, an intensive care unit is a specially staffed and equipped in a separated area in a hospital, dedicated to the management of patients with life-threatening illnesses [1]. Therefore, this study was focused on the mortality rate of patients admitted into the ICU conferring to these variables: age group, gender, and the distribution of diseases on admission.

\section{Method}

A descriptive retrospective study conducted on patients admitted into the Intensive Care Unit, University of Abuja Teaching Hospital, (UATH). All records of patients admitted to the Intensive Care Unit from May 2002 to April, 2020 were analyzed. Ethical approval was obtained from the University of Abuja Teaching Hospital, Health Research and Ethics Committee. The data were collated from the ICU admission/discharge register. This was entered on a spreadsheet designed for the study and data was analyzed using IBM SPSS version 26.0. All the patients considered for this study were within the age range of $1-89$ years. A Purposeful Sampling technique was used where the total sample of all patients admitted to the ICU during the period under review was used. Information on socio-demographic characteristics like gender, age, occupation and religion were collected. Diagnosis on admission, the outcome was also obtained for all the patients that were admitted. Categorical variables were described as frequencies and percentages. The association between categorical variables was tested using Chi-square test and level of significance was set at a p-value $<0.05$.

\section{Results}

Table 1. Socio-demographic characteristics of the patients.

\begin{tabular}{lll}
\hline Variable & Frequency & Percentage \\
\hline Gender & & \\
Female & 1062 & 51.1 \\
Male & 1016 & 48.9 \\
Total & 2078 & 100 \\
Age grouping & & \\
Infants (1 - 11 months) & 82 & 3.9 \\
Under-five (12-59 months) & 67 & 3.2 \\
Children (5-17 years) & 141 & 6.8 \\
Adults (18-64 years) & 1692 & 81.4 \\
Elderly (65 and above) & 96 & 4.6 \\
Total & 2078 & 100 \\
Occupation & & \\
Skilled & 477 & 23 \\
Unskilled & 1340 & 64.5 \\
Under - care & 194 & 9.3 \\
Retiree & 67 & 3.2 \\
Total & 2078 & 100 \\
Religion & & \\
Christianity & 1233 & 59.3 \\
Islam & 836 & 40.2 \\
Others & 9 & 0.4 \\
Total & 2078 & 100 \\
\hline
\end{tabular}

Table 2. Case distribution of the patients.

\begin{tabular}{lll}
\hline Grouped Diagnoses & Frequency & Percentages \\
\hline Medical & 186 & 9 \\
Obstetric and Gynaecologic & 510 & 24.5 \\
Paediatrics & 110 & 5.3 \\
Surgical & 1272 & 61.2 \\
Total & 2078 & 100 \\
\hline
\end{tabular}

Table 3. Transferred Units of the Patients.

\begin{tabular}{lll}
\hline Unit transferred & & \\
\hline A/E & 16 & 0.7 \\
ENT & 7 & 0.3 \\
HOME & 20 & 1 \\
LAMA & 2 & 0.1 \\
MEDICINE & 50 & 2.4 \\
MORTUARY & 716 & 34.5 \\
OBS/GYN & 355 & 17.1 \\
ORTHOPAEDICS & 16 & 0.7 \\
PAEDIATRICS & 84 & 4 \\
RENAL UNIT & 1 & 0 \\
SURGERY & 811 & 39 \\
Total & 2078 & 100 \\
\hline
\end{tabular}

\section{OUTCOME OF PATIENTS IN THE ICU}

The overall prevalence of mortality of ICU in the years under review was $34.6 \%$. Mortality rate per year of $51.4 \%$ was highest in 2017 while $17.9 \%$ was the lowest in 2008 . Thus, the result showed that prevalence varied from year to year. 


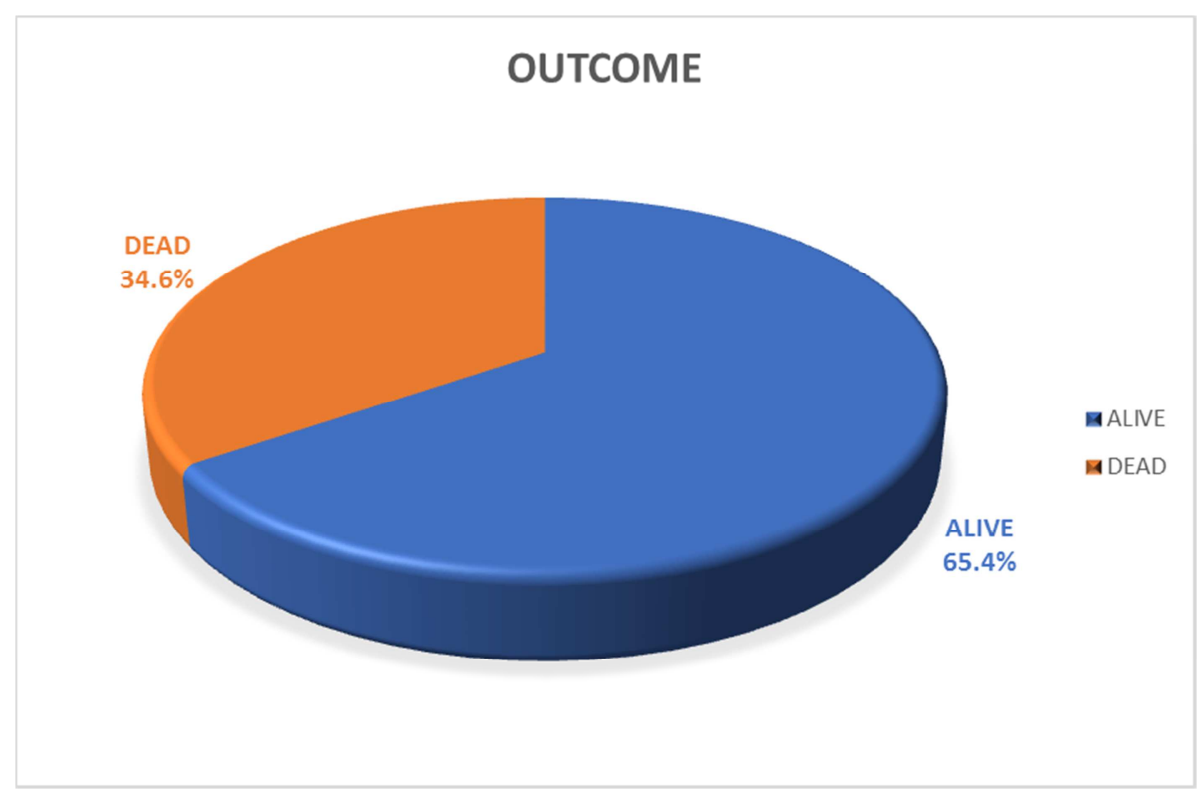

Figure 1. Prevalence of patients 'mortality.

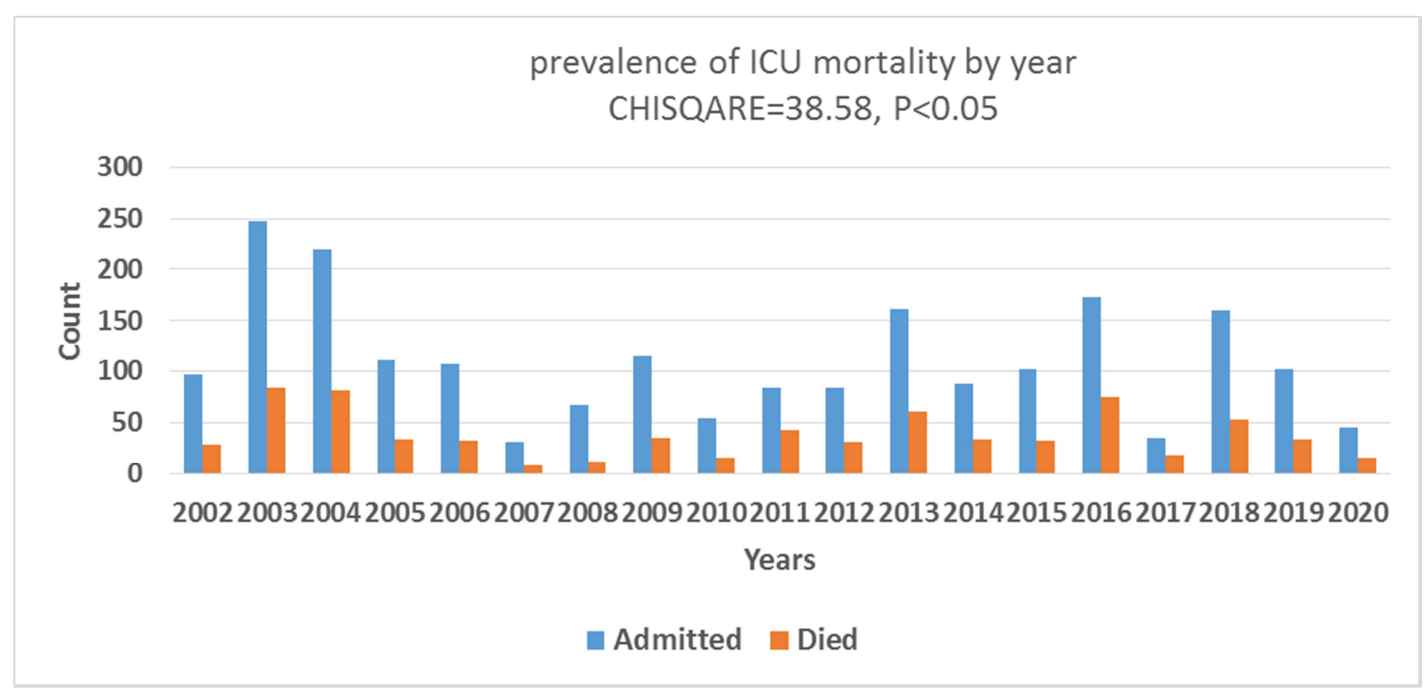

Figure 2. Prevalence of ICU mortality by year.

Table 4 reveals patients' general characteristics and mortality and shows that, out of 1062 females, 322 (30.3\%) died, while out of 1016 male patients, 396 (39\%) died. The significant

Considering the association between the various sociodemographic variables and mortality, table 4 reveals that more males died than females, implying the statistical significant association between gender and mortality $(\mathrm{P}<0.01)$ among the admitted patients in the study period. In the same vein, there is a statistical significant association between religion and mortality $(\mathrm{P}<0.01)$. The same submission can be seen between diagnosis and mortality as there is a statistical significant association between diagnosis and mortality among the admitted patients in this study period.

Furthermore, $29.3 \%$ died among the infants, $31.3 \%$ out of patients who are children died, $34.7 \%$ died among adult patients, $44.8 \%$ of elderly patient admitted to ICU died. In terms of religion, $31.5 \%$ of Christian patients died, $38.3 \%$ of Muslim patients lost their lives. More patients with unknown faith lost their lives because they came into the unit as unknown named patients. Hence, the prevalence of mortality in ICU varies from religion to religion. $33.1 \%$ of skilled patients died, $35.8 \%$ of unskilled patients died, $37.3 \%$ of retiree patients lost their lives. For medical diagnosis, $69.9 \%$ of patients who were diagnosed of medical related aliment died, $26.3 \%$ died from obstetric and gynecologic related diagnosis, $1.8 \%$ of pediatric related aliments died, while $35.5 \%$ of surgical cases died. This result implies that mortality rate differs from diagnosis to diagnosis, more patient diagnosed with medical related diseases died. 
Table 4. Factors associated with mortality among the patients.

\begin{tabular}{|c|c|c|c|c|c|}
\hline \multirow{2}{*}{ Gender } & \multicolumn{3}{|l|}{ Outcome } & \multirow{2}{*}{ Chi-square } & \multirow{2}{*}{ p-value } \\
\hline & Alive & Died & Total & & \\
\hline \multicolumn{6}{|l|}{ Gender } \\
\hline Female & $740(69.7)$ & $322(30.3)$ & $1062(100.0)$ & \multirow[t]{2}{*}{17.205} & \multirow[t]{2}{*}{$<0.001 *$} \\
\hline Male & $620(61.0)$ & $396(39.0)$ & $1016(100.0)$ & & \\
\hline \multicolumn{6}{|c|}{ Age classification } \\
\hline Infants & $58(70.7)$ & $24(29.3)$ & $82(100.0)$ & \multirow[t]{6}{*}{6.809} & \multirow[t]{6}{*}{0.146} \\
\hline Under-five & $46(68.7)$ & $21(31.3)$ & $67(100.0)$ & & \\
\hline Children & $98(69.5)$ & $43(30.5)$ & $141(100.0)$ & & \\
\hline Adults & $1105(65.3)$ & $587(34.7)$ & $1692(100.0)$ & & \\
\hline Elderly & $53(55.2)$ & $43(44.8)$ & $96(100.0)$ & & \\
\hline \multicolumn{4}{|l|}{ Religion } & & \\
\hline Christianity & $844(68.5)$ & $389(31.5)$ & $1233(100.0)$ & \multirow[t]{4}{*}{27.095} & \multirow[t]{4}{*}{$<0.001 *$} \\
\hline Islam & 516 (61.7) & $320(38.3)$ & $836(100.0)$ & & \\
\hline Unknown & 0 & $9(100.0)$ & $9(100.0)$ & & \\
\hline \multicolumn{4}{|l|}{ Occupation } & & \\
\hline Skilled & $319(66.9)$ & $158(33.1)$ & $477(100.0)$ & \multirow[t]{5}{*}{4.910} & \multirow[t]{5}{*}{0.179} \\
\hline Unskilled & $860(64.2)$ & $480(35.8)$ & $1340(100.0)$ & & \\
\hline Paediatrics & $139(71.6)$ & $55(28.4)$ & $194(100.0)$ & & \\
\hline Retiree & $42(62.7)$ & $25(37.3)$ & $67(100.0)$ & & \\
\hline \multicolumn{4}{|l|}{ Diagnosis } & & \\
\hline Medical & $56(30.1)$ & $130(69.9)$ & $186(100.0)$ & \multirow[t]{4}{*}{170.844} & \multirow[t]{4}{*}{$<0.001^{*}$} \\
\hline Obs/Gyn & $376(73.7)$ & $134(26.3)$ & $510(100.0)$ & & \\
\hline Paediatrics & $108(98.2)$ & $2(1.8)$ & $110(100.0)$ & & \\
\hline Surgical & $820(64.5)$ & $452(35.5)$ & $1272(100.0)$ & & \\
\hline
\end{tabular}

\section{Discussion}

In this study, there was a higher number of females (51.1\%) while $48.9 \%$ were males as compared to other studies which stated the opposite. In the research study by R. A. Fowler et al; 2007 who made an assertion that, the proportion of admissions due to specific diagnoses varied according to sex, greater numbers of men than of women were admitted to an ICU with a medical diagnosis or a non -obstetric surgical diagnosis, which was in consonant with the study done by Hendry R. Sawe et al; 2014, who also claimed that, male predominance in their study, may in some extent, reflect the prevalence of trauma, long shown to have a working age male predominance and other researchers studies also agreed with the male predominance. [3-6]. In contrast to the aforementioned studies, this study showed that females are higher than males on admission at the Intensive Care Unit in the University of Abuja. The reason for this deviation from our study may be associated with increased admission from Obstetrics and Gynecology department.

Furthermore, it is shown in this study that, there were more adults (18 - 64 years) with $81.4 \%$ of the population of $\mathrm{N}$ Valid (2078), with the age mean of 34.07, median of 33.0, minimum of less than a year and maximum of 85 years. Similarly, there was a research finding [6] with middle age group (20 - 59 years) and this accounted for $66.9 \%$ of admission, while another study [5] had more of elderly (37 97 years) with a median age of 70 years. The highest distribution is the surgical cases which were as a result of Road Traffic Accident (RTA), Severe Head Injury, Severe Burns with mortality rate of $35.5 \%$ which is similar to the findings by Poluti et al; 2016 [6].

Also, in this study, it was discovered that, the surgical cases being the highest in the distributions is probably associated with the proximity of the facility to the Federal Highway. Furthermore, it was discovered that Obstetrics and Gynecology was the second highest admissions in the Intensive Care Unit (ICU) due to the factor of non-proximity of the hospital to many rural areas, with most of these rural areas having poor health awareness and there exists gaps in the capacity of the primary health care facilities in rendering high-quality maternal and child health services, leading to clients resorting to traditional procedures and absence of regular Ante Natal Care (ANC) at the primary health care centers; consequently, the resultant effect of increased complications from pre/post-eclampsia, Postpartum Hemorrhage (PPH), Cesarean Section and poor intra-facility referral system.

In another multi-center observational study which also revealed that, the majority of patients admitted to ICU were female and younger productive age groups, 19-39 years old which are in line with other studies conducted in SubSaharan African countries [7-13]. This finding corroborated with this study. Contrarily, another study discovered a higher rate among male gender which was discovered in the age group among low-income countries might be due to engagement in violence, road traffic accident and relatively educated with high health-seeking behavior. While, the rate of admission to ICU in developed nations was among older patients that might be due to a sedentary lifestyle and high prevalence of a non-communicable disease among these patients [14-17].

This study also revealed that, the surgical cases being the highest in its distributions was ascertained to be due to the proximity of the facility, which is accessible to the Federal Highway. Furthermore, Obstetrics and Gynecology been the second highest admissions in the Intensive Care Unit (ICU) due 
to the factor of proximity of the hospital to many rural areas, most of these rural areas have poor health awareness, hence they resorted to traditional procedures and absence of regular Ante Natal Care (ANC); consequently, the resultant effect of increased complications from pre/post-eclampsia, Postpartum Hemorrhage (PPH), Cesarean Section and poor referral system. Additionally, UATH being a referral Centre and most likely serves a large population that does not have ICU services.

According to the study done by Chukwuemeka O. Eze et al; 2020 [18] "mortality rate was $40.8 \%$. It is very high as 2 out of every 5 ICU admissions died". Similarly, other studies in Africa also reported 34\% - 43\% [11, 19, 20] but higher than $8 \%-18 \%$ reported in the USA and France $[21,22]$. This high mortality rate is due to late presentation of patients, availability of limited number of trained staff and lack of adequate life support equipment in most developing countries.

In this study, the unskilled workers which are summed up to be population across all the grouped diagnosis with more attention to surgical being the highest population in the percentage of $860(64.2 \%)$ were alive while $480(35.8 \%)$ were dead and this is due to high incidence of trauma from road traffic accidents due to un-licensed and un-trained drivers and motor-cyclists, poor road maintenance and lack of willingness from the government in the implementation of road safety measures in developing countries. Furthermore, most patients from other grouped diagnosis i.e. medical, pediatrics and obstetrics/gynecology presented late to the hospital due to poor referral system from the primary health care level, inaccessibility of the hospitals, ignorance, poverty and with a resultant effect of poor prognosis which leads to life threatening agreed with the study done by Labinjo, M., and Akande, T. M 2009 [23, 24].

Overall, the facility is a referral Centre and most likely serves a large population that does not have ICU services. The outcome of this study showed the frequency $(f)$ of patients who were alive at 1360 with percentage of $65.4 \%$ and the death frequency $(f)$ of 718 which accounted for $34.6 \%$, and this may be due to late presentation of patients to the facility, limited number of trained staff and lack of adequate life support equipment.

\section{Limitations of the Study}

This study has its scope of aims and objective, but there were some observed limitations. Firstly, this is a retrospective study using the Intensive Care Unit admission and discharged record, which was limited. The study was limited to the only teaching hospital in the Federal Capital Territory. Hence, this would limit generalization of the result. This study does not provide other outcome variables that can be used to assess quality of intensive care such as death rate within the first 24 hours, mean number of ICU days of stay per survivor and the financial implications of patients' period of stay in the unit. This is due to the limited domain from the records. There will be need to include information that would allow recording of this indices in the ICU records. The need for the institutionalization of Electronic Health Record at this point cannot be over-emphasized. This would ensure that all the records needed are imputed which can be easily accessed when required for studies like this.

\section{Conclusion}

The rate of patients' survival in the Intensive Care Unit is relatively low even with the availability of functional equipment such as suctioning machine, mechanical ventilator, Arterial Blood Gas Analyzer (ABG), bed-side cardiac monitor, regular supply of electricity and central piped oxygen. This may be due to the historical period of time the patients are brought, as the intensive care unit is seen as the last option for intensive care, therefore the patients' condition might have worsened with poor prognosis before bringing them into the unit. There is a need for training and re-training of Doctors and Nurses, including other health care workers, caring for these patients with particular attention to the use of various prognostic tools for assessing and predicting the severity of initial admission into the Intensive Care Unit which includes Acute Physiology and Chronic Health Evaluation (APACHE) II among others evidenced study done by Christie Omolola Adams et al; 2020 [25] which revealed that, there was no optimal knowledge and awareness of the utilization of this prognostic tools.

\section{Acknowledgements}

We will like to acknowledge the contributions of all the authors, co-authors and the trained research assistant (Esther Adams) and co-operations of the Intensive Care Nurses in the University of Abuja Teaching Hospital - Gwagwalada.

This research was a team work and self-sponsored neither was there any conflict of interest.

\section{References}

[1] John C Marshall et. al, What is an Intensive Care Unit (ICU): A Report of the Task Force of the World Federation of Societies of Intensive and Critical Care Medicine July 2016 Journal of Critical Care 37 DOI: 10.1016/j.jcrc.2016.07.015.

[2] Lluís Blanch Torra et. al, Triage Decisions for ICU Admission: report from the Task Force of the World Federation of Societies of Intensive and Critical Care Medicine June 2016 Journal of Critical Care 36, DOI: 10.1016/j.jcrc.2016.06.014.

[3] RA Fowler, 2007 cited by Robert A et. Al Sex-and age-based differences in the delivery and outcomes of critical care December 04, 2007177 (12) 1513-1519; DOI: https://doi.org/10.1503/cmaj.071112.

[4] Hendry R Sawe et. al, Disease patterns and clinical outcomes of patients admitted in intensive care units of tertiary referral hospitals of Tanzania, BMC Int Health Human Rights. 2014; 14: 26. Published online 2014 Sep 23. doi: 10.1186/1472-698X-14-26.

[5] Emma Larsson, Erik Zettersten, Gabriella Jäderling, Anna Ohlsson, and Max Bell, The influence of gender on ICU admittance, Scand J Trauma Resusc Emerg Med. 2015; 23: 108. Published online 2015 Dec 24. doi: 10.1186/s13049-015-0191-2. 
[6] Poluyi EO, Fadiran OO, Poluyi CO, et. al. Profile of Intensive Care Unit Admissions and Outcome in a Tertiary Care Centre of a Developing Country in West Africa: A 5-year Analysis. J. Intensive \& Crit Care 2016, 2: 3.

[7] U. Okafor Challenges in critical care services in Sub-Saharan Africa: perspectives from Nigeria/Indian J. Crit. Care Med.: Peer-reviewed, 13 (1) (2009), p. 25 Official Publication of Indian Society of Critical Care Medicine.

[8] A. Agalu, M. Woldie, Y. Ayele, W. Bedada Reasons for admission and mortalities following admissions in the intensive care unit of the specialized hospital, in Ethiopia - Int. J. Med. Med. Sci., 6 (9) (2014), pp. 195-200.

[9] K. Gidey, A. Hailu, A. Bayray Pattern and outcome OF medical intensive care unit admissions to Ayder ComprehensiveSpecialized Hospital IN tigray, Ethiopia Ethiop. Med. J., 56 (2017).

[10] G. Lema, H. Tessema, N. Mesfin, D. Fentie, N. Arefaynie Admission Pattern, Clinical Outcomes and Associated Factors Among Patients Admitted in Medical Intensive Care Unit at University of Gondar Comprehensive and Specialized Hospital, Northwest Ethiopia - A retrospective cross-sectional study (2019).

[11] H. R. Sawe, J. A. Mfinanga, S. J. Lidenge, B. C. Mpondo, S. Msangi, E. Lugazia, et al. Disease patterns and clinical outcomes of patients admitted in intensive care units of tertiary referral hospitals of Tanzania BMC Int. Health Hum. Right, 14 (1) (2014), p. 26.

[12] I. U. Ilori, Q. N. Kalu Intensive care admissions and outcome at the University of Calabar teaching hospital, Nigeria J. Crit. Care, 27 (1) (2012), pp. e1-e4 105.

[13] Z. Smith, Y. Ayele, P. McDonald Outcomes in critical care delivery at Jimma University Specialized Hospital, Ethiopia Anaesth. Intensive Care, 41 (3) (2013), pp. 363-368.

[14] L. T. Cardoso, C. M. Grion, T. Matsuo, E. H. Anami, I. A. Kauss, L. Seko, et al. Impact of delayed admission to intensive care units on mortality of critically ill patients: a cohort study - Crit. Care, 15 (1) (2011), pp. 1-8.

[15] E. Gayat, A. Cariou, N. Deye, A. Vieillard-Baron, S. Jaber, C. Damoisel, et al. Determinants of long-term outcome in ICU survivors: results from the FROG-ICU study Crit. Care, 22 (1) (2018), p. 8.

[16] C.-A. Liang, Y.-C. Lin, P.-L. Lu, H.-C. Chen, H.-L. Chang, C.C. Sheu Antibiotic strategies and clinical outcomes in critically ill patients with pneumonia caused by carbapenemresistant Acinetobacter baumannii - Clin. Microbiol. Infect., 24 (8) (2018), pp. e1-e7 90.
[17] J. L. Moran, P. Bristow, P. J. Solomon, C. George, G. K. Hart, Australian, et al. Mortality and length-of-stay outcomes, 1993-2003, in the binational Australian and New Zealand intensive care adult patient database Crit. Care Med., 36 (1) (2008), pp. 46-61.

[18] Chukwuemeka O. Eze1 et al Internal Medicine Department, Alex Ekwueme Federal University Teaching Hospital Abakaliki (AEFUTHA), Ebonyi State, Nigeria. - DOI: 10.4236/wjcd.2020.107047 World Journal of Cardiovascular Diseases - Vol. 10 No. 7, July 2020.

[19] Onyekwulu, F. A. and Anya, S. U. Pattern of Admission and Outcome of Patients Admitted into the Intensive Care Unit of University of Nigeria Teaching Hospital Enugu: A 5-Year Review. Nigerian Journal of Clinical Practice, 18 775-779. (2015) - https://doi.org/10.4103/11193077.163291 .

[20] Isamade, E. S., Yiltok, S. J., Uba, A. F., Isamade, E. I. and Daru, P. H Intensive Care Unit Admissions in the Jos University Teaching Hospital. Nigerian Journal of Clinical Practice, 10, 156-161 (2007).

[21] Mukhopadhyay, A., Tai, B. C., See, K. C., Ng, W. Y., Lim, T. K., Onsiong, S., et al. Risk Factors for Hospital and LongTerm Mortality of Critically Ill Elderly Patients Admitted to an Intensive Care Unit. BioMed Research International, 2014, Article ID: 960575. https://doi.org/10.1155/2014/960575 (2014).

[22] Azoulay, E., Adrie, C., De Lassence, A., Pochard, F., Moreau, D., Thiery, G., Cheval, C., Moine, P., Garrouste-Orgeas, M., Alberti, C., et al Determinants of Post intensive Care Unit Mortality: A Prospective Multicenter Study. Critical Care Medicine, 31, 428-432 - (2003) https://doi.org/10.1097/01.CCM.0000048622.01013.88.

[23] Labinjo, M., Juillard, C., Kobusingye, O. C. and Hyder, A. A. The Burden of Road Traffic Injuries in Nigeria: Results of a Population-Based Survey. Injury Prevention, 15, 157-162. https://doi.org/10.1136/ip.2008.020255 - 2009.

[24] Akande, T. M. and Owoyemi, J. O. Health-Seeking Behaviour in Anyigba, North-Central, Nigeria. Research Journal of Medical Sciences, 3, 47-51-2009.

[25] Christie Omolola Adams, et al Assessment of Knowledge and Awareness of Acute Physiology and Chronic Health Evaluation (APACHE) II Tool Among Intensive Care Nurses in a Tertiary Institution International Journal of Anesthesia and Clinical Medicine 2020; 8 (2): 47-54 http://doi: 10.11648/j.ijacm.20200802.14. 